\title{
DISPUTAS IDENTITÁRIAS: PÓS-MODERNIDADE E TEORIA QUEER
}

\section{IDENTITY DISPUTES: POST-MODERNITY AND QUEER THEORY}

Cleber Souza Meneses ${ }^{1}$

\section{RESUMO}

Neste artigo discorreremos sobre identidades de gênero, partindo da premissa que toda identidade é uma construção social e relacional e todo indivíduo é fragmentado e múltiplo. Tomando como referência@s transgêneros como sujeit@ ${ }^{2}$ da pósmodernidade, iniciaremos com uma revisão bibliográfica para compreender como a mulher lidou historicamente com o patriarcalismo. Fazendo uma relação entre a construção do Ser mulher em uma relação de alteridade com o seu Outro, o homem, perceberemos como os discursos das instituições sociais as categorizavam com um grau de inferioridade, uma vez que por muito tempo foi nomeada e construída pelos discursos masculinos. Esse percurso de primeiro pensar a construção da mulher foi necessário para compreendermos como a população trans feminina lidou com a construção de suas identidades perante as relações de poder, em um debate a partir da teoria queer, refletindo como el@s tornaram-se sujeit@s "fora da norma” (abjetos) em uma sociedade constituída pelo viés da heteronormatividade.

Palavras-chave: Identidade. Sexualidade. Patriarcado. Teoria Queer.

\footnotetext{
${ }^{1}$ Mestre em Cultura e Sociedade (UFBA). Doutorando em Sociologia (UFS); Membro do Grupo de Estudos e Pesquisa Processos Identitários e Poder (GEPPIP/CNPq/UFS). E-mail: cleber.cultura@gmail.com

${ }^{2}$ Usaremos neste artigo o @ em substituição ao marcador gramatical que define o gênero ( $\mathrm{a}=$ feminino e $\mathrm{o}=$ masculino), como uma estratégia político-teórica de quebrar com o binarismo e desenvolver uma forma de expressar um gênero neutro que sintetize tod@s.
} 


\begin{abstract}
In this article we will discuss gender identities starting from the premise that all identity is a social and relational construction and every individual is fragmented and multiple. Taking transgenders as a reference of postmodernity subjects, we will start with a bibliographical review to understand how women historically dealt with patriarchy. In order to make a relation between the construction of the Being woman in a relation of otherness with the Other, the man, we will perceive how the discourses of the social institutions categorized them with a degree of inferiority, since for a long time it was named and constructed by the male speeches. This path of first thinking about the construction of women was necessary to understand how the female trans population dealt with the construction of their identities in the face of power relations, through a debate based on queer theory, reflecting how they became subjects "outside the Norm "(abjects) in a society constituted by the heteronormativity bias.
\end{abstract}

Keywords: Identity. Sexuality. Patriarchate. Queer Theory. 


\section{Introdução}

Este artigo foi construído a partir de reflexões teóricas e revisões bibliográficas com o objetivo de apresentar as construções identitárias do gênero feminino, tomando como referência o processo relacional, que parte da premissa que precisamos do Outro para nos definirmos. Antes de fazer a imersão no tema do gênero propriamente dito, faremos uma breve explanação sobre o conceito de identidade de forma mais geral, em uma perspectiva pós-moderna.

Afinal, o que é ter uma identidade? Para que serve? Qual sua função? No que importaria isso para um grupo? Para tecer essa reflexão sobre identidades como um processo de construção social, iremos tomar como referência na primeira seção as contribuições teóricas de Manuel Castells e Zigmunt Bauman que são autores, dentre outros tantos, que se distinguem mas possuem como ponto de intersecção a multiplicidade do ser e as relações de poder (ENNES, MARCON, 2014).

Na segunda seção discutiremos a construção das identidades sexuais e de gênero, que se subdivide em: 1- Uma análise do patriarcalismo do ponto de vista de Pateman; 2 - A construção das identidades de gênero seguindo análises distintas do feminismo e da teoria queer, e fechando com uma discussão sobre as sexualidades desviantes por meio da teoria queer. A escolha deste caminho é para compreendermos como chegamos ao sistema binário do sexo (masculino e feminino) e de que maneira a heterossexualidade tornou-se compulsória.

\section{Identidades em construção no pensamento contemporâneo}

A todo o momento somos questionados sobre as diversas identidades que possuímos e, da mesma forma que uma roupa, despimos e vestimos a identidade que melhor nos cabe a cada contexto social, em alguns casos as sobrepomos para reificar ou desestabilizar a imagem que queremos representar.

Quem sou eu? Nunca foi uma pergunta tão difícil de ser respondida, uma vez que as identidades eram pré-determinadas e fixas, mas hoje sua fluidez e multiplicidade nos leva a refletir bastante antes de responder, 
e quase sempre não conseguindo responder de forma objetiva. Esta é uma característica do sujeito contemporâneo, um ser fragmentado e imerso em um emaranhado de identidades. E é desta maneira que Castells (1999) entende a construção da identidade:

[...] entendo por identidade o processo de construção de significado com base em um atributo cultural, ou ainda um conjunto de atributos culturais inter-relacionados, o(s) qual(ais) prevalece $(\mathrm{m})$ sobre outras fontes de significado. Para um determinado indivíduo ou ainda um ator coletivo, pode haver identidades múltiplas. No entanto, essa pluralidade é fonte de tensão e contradição tanto na autorepresentação quanto na ação social. (CASTELLS, 1999, p. 22)

A identidade então só pode ser compreendida com base na cultura e contexto histórico específico, sendo construída de forma relacional, com base nos significados que são de conhecimento de determinada sociedade e do próprio indivíduo. Ela se constitui no mundo das ideias e se materializa através das práticas e discursos. Porém, as identidades são frutos de tensões e contradições internas (indivíduo) bem como sociais (coletivo), marcadas por relações de poder. Partindo desse pressuposto, Castells desenvolve três origens distintas da construção das identidades: a legitimadora; a de resistência; e a de projeto.

A identidade legitimadora está relacionada ao campo institucional que constitui a sociedade, tais como o Estado (em suas três esferas: executivo, legislativo e judiciário), as Igrejas (religiões), as Escolas (educação), a medicina, os sindicatos, partidos, dentre tantas outras instituições que fazem uso dos aparatos de poder para legitimar identidades através da imposição, alienação, disciplinação e padronização.

Já a identidade de resistência é considerada por Castells como o tipo mais importante, uma vez que, através do questionamento e inversão dos discursos legitimadores que vimos acima, provoca tensões e rompe com a resistência às mudanças. A depender do contexto histórico e o grau de institucionalização social temos como resultado uma sociedade que resiste e permanece sólida, ou que se torna líquida e fragmentada como um arquipélago povoado por tribos distintas. 
Chegamos então à identidade de projeto, que são formas organizadas de resistência que levam a uma redefinição das posições sociais dentro de uma determinada estrutura cultural, social e/ou econômica. Desta maneira esta identidade apresenta um "novo" projeto de vida, com subjetividades diferentes das até então reconhecidas como legítimas. Este tipo de identidade geralmente começa como resistência e pode acabar se tornando uma identidade legitimadora, à medida que venha a se tornar uma ideia dominante nas instituições sociais.

Com base em Castells temos identidades que são voláteis e sem essência, uma vez que as relações de poder que permeiam essa negociação e disputa no contexto social promovem um trânsito constante. O que hoje pode ser uma identidade de resistência, amanhã poderá ser uma identidade de projeto que mais à frente poderá se tornar uma identidade legitimadora.

E nessa cultura pós-moderna que vivemos hoje, constituída por fragmentos que se conectam e outras vezes não, permeada por situações efêmeras e que circulam rapidamente no mudo das subjetivações, deixanos cada vez mais com uma sensação de deslocados por nos sobrecarregar de identidades. “As 'identidades' flutuam no ar, algumas de nossa própria escolha, mas outras infladas e lançadas pelas pessoas em nossa volta, e é preciso estar em alerta constante para defender as primeiras em relação as últimas" (BAUMAN, 2005, p. 18). Desta maneira, estamos em um eterno exercício de (re)negociação para se reafirmar e determinar as afiliações sociais a que desejamos pertencer.

Essa liquidez moderna nos conduz a se afastar das identidades do modo clássico, sólidas e naturalizadas, ao mesmo tempo em que causa desconforto e insegurança lidar com nossas identidades em movimento. Tornamo-nos seres contingentes, com uma diversidade de identidades novas e ainda não exploradas que surgem como opção para@s sujeit@s, que precisam ser administradas, acomodadas, negadas, aceitas e/ou ressignificadas.

[...] flutuar sem apoio num espaço pouco definido, num lugar teimosamente, perturbadoramente, "nem-um-nemoutro", torna-se a longo prazo uma condição enervante e produtora de ansiedade. Por outro lado, uma posição fixa dentro de uma infinidade de possibilidades também não é uma perspectiva atraente. (BAUMAN, 2005 p. 35) 
Vivemos em um mundo movediço, caracterizado pela ambivalência e pelas hierarquias de poder. Sobre este último aspecto há três grupos distintos: os que têm liberdade de escolha das identidades que @s representa (grupo hegemônico); @s que possuem identidades determinadas pelos outros (estigmatizada); e @s que têm negado o direito a possuir uma identidade (subclasse). Sobre essa terceira categoria Bauman (2005) diz:

O significado da "identidade da subclasse" é a ausência da identidade, a abolição ou negação da individualidade, do "rosto" - esse objeto do dever ético e da preocupação moral. Você é excluído do espaço social em que as identidades são buscadas, escolhidas, construídas, avaliadas, confirmadas ou refutadas. (BAUMAN. 2005, p. 46)

Apesar de termos uma diversidade de identidades a serem acionadas pel@s sujeit@s, segundo Bauman, temos uma diferenciação entre as pessoas com base nas relações de poder. Há um reduzido grupo de privilegiados (livre acesso a todas as alternativas, tanto para adotar como rechaçar as identidades); um elevado grupo de oprimidos (que vivem em uma eterna luta de combate aos estereótipos) e um terceiro grupo que vive à margem, os "sem-identidade" (seres abjetos).

Voltando à questão da ambivalência da identidade, ela pode ser interpretada como uma eterna batalha. De um lado os que combatem a opressão e a abjeção, desejando ter uma identidade reconhecida e desta maneira adquirindo visibilidade. E do outro, os grupos hegemônicos que defendem a homogeneização e estão em constante reificação de normas e combatendo qualquer "desvio" e "anormalidade", considerando que quem os pratica precisa ser enquadrado ou rechaçado e punido.

Essa disputa pelo poder de determinar algo ou alguém não ocorre somente nas relações sociais, mas também dentro do campo científico que sempre foi e será um campo de batalha, as ciências vivem duelando pra definir qual o discurso mais legítimo.

Com base nesses teóricos que pensam @s sujeito@s modern@s como fragmentados e múltiplos, que estão inseridos em um mundo social tão complexo quanto el@s, chegamos a perceber o quão difícil é responder a uma simples pergunta: “quem sou eu?”. Nossas identidades são cada 
vez mais fluídas, efêmeras, contextuais, sobrepostas, inclusivas, excludentes, políticas e estereotipadas, compostas pelas/nas relações de poder e que a sua identidade de agora pode não ser a mesma de momentos depois, tanto do ponto de vista da autorreferência como do ponto de vista do outro.

\section{A construção das identidades sexuais e de gênero}

Nesta seção iremos discutir as identidades sexuais e de gênero, tomando como referência as relações de poder que as (trans)formam, problematizando como as identidades sexuais se constituíram através das diversas disputas permeadas por repressão, transgressão, normatização e resistência? Sob quais estruturas aconteceram essas batalhas? Em que medida a sexualidade deixa de ser um assunto privado para se tornar público? Estas e outras questões pertinentes ao assunto serão abordadas introdutoriamente aqui.

Partiremos do patriarcalismo como estrutura de análise, por ser "uma das estruturas sobre as quais se assentam todas as sociedades contemporâneas" (CASTELLS, 1999, p. 169). Desta maneira, compreenderemos como chegamos ao sistema binário do sexo (masculino e feminino) e de que maneira a heterossexualidade tornouse compulsória e a única identidade sexual legítima no processo de construção sociocultural.

\subsection{Os patriarcalismos segundo Pateman}

Faz-se necessário relatar que o termo patriarcalismo possui diversas interpretações e abordagens distintas, umas mais amplas e outras nem tanto. A concepção de patriarcalismo que adotaremos aqui é a de Carole Pateman, uma feminista inglesa nascida em 1940, que em seu livro sobre o Contrato Sexual (1988) critica os contratualistas clássicos (Locke, Hobbes e Rousseau) até os mais recentes, demonstrando que o patriarcalismo jamais deixou de existir, apenas muda de forma e se constitui no que a autora define como patriarcalismo moderno. 
Pateman apresenta três tipos de argumentação patriarcal que não são excludentes: o tradicional; o clássico; e o moderno. No tradicional temos todas as relações de poder incorporadas ao regime paterno e toma a família patriarcal como referencial da sociedade política. Nesta versão do patriarcalismo o pai era o único e soberano dentro da esfera familiar (poderes plenos sobre a família), foi desenvolvido no período da Idade Média até o Séc. XVII.

O segundo tipo de patriarcado (clássico) era forjado sob a ideia "de que os filhos nasciam submetidos aos pais e estavam, portanto, a eles subjugados politicamente. $\mathrm{O}$ direito político era natural e não uma convenção" (PATEMAN, 1993, p. 45). Nesse tipo a reprodução do pai (interpretada como monogênica) dá ao homem a supremacia nas relações de poder que saem do privado (família patriarcal) e se estendem ao público (civil).

No patriarcado moderno temos um sistema que deixa de ser paterno para ser masculino, ou seja, "as mulheres são subordinadas aos homens enquanto homens, ou enquanto fraternidade" (PATEMAN, 1993, p. 18). É uma versão aprimorada do patriarcado clássico, baseado no contrato original, que destitui o poder do pai como natural, mas mantém o direito natural conjugal dos homens (os únicos considerados livres indivíduos) sobre as mulheres, como se cada homem tivesse além da propriedade em sua pessoa, o direito natural de poder sobre a sua mulher.

Apesar dos contratualistas defenderem a ideia do fim do patriarcado, usando como argumento a ideia de indivíduos (homens) "livres" do contrato original, "o contrato está longe de se contrapor ao patriarcado; ele é o meio pelo qual se constitui o patriarcado moderno" (PATEMAN, 1993, p. 17).

Pateman considera que toda análise do Estado deve ter como premissa a concepção do patriarcado, uma vez que todo Estado é patriarcal, regido por um contrato original composto por duas partes, o contrato social (liberdade do indivíduo - o homem) e o contrato sexual (em que ocorre a sujeição da mulher ao homem), que segundo a autora, foi renegado à invisibilidade pelos teóricos clássicos, sendo a sua grande crítica desenvolvida nesta obra. 
Após 18 anos da publicação desta análise crítica de Pateman (1988) ${ }^{3}$, temos um cenário diferente no que tange ao contrato social (direitos), em que as mulheres conquistaram cada vez mais espaço e voz, a liberdade e igualdade jurídica está mais próxima da equidade entre homens e mulheres, porém, não há como negar que as práticas patriarcais no âmbito familiar e sociopolítico ainda permanecem arraigadas na sociedade contemporânea de maneira camuflada. E esta nova versão do patriarcalismo, ao qual chamarei aqui de "patriarcalismo pós-moderno", provoca o surgimento das identidades de resistência e identidades de projeto (que vão além da categoria mulher), questionando essas identidades fixas que foram legitimadas, tendo o homem como superior e todas as demais identidades sendo subjugadas a esse constructo social realizado por relações de poder.

\subsection{A construção das Identidades de Gênero}

Como desestabilizar o poder relacionado ao gênero? Tornando instável e flexível as normas e identidades e desnaturalizando os discursos. Quando se pensa em romper com o binarismo de gênero desencadeia-se uma ameaça a todo um sistema político, econômico e social que foi constituído e se sustenta com base nesses discursos naturalizados e tomados como verdade única. Por isso é tão difícil questionar, desconstruir e promover uma reflexão sobre o que se entende por gênero, porque para isso se faz necessário legitimar novas terminologias, novas histórias, novos sujeitos.

[...] é necessário abrir a caixa preta dos processos de construção do gênero e da sexualidade que, se são construídos, podem ser desconstruídos, reconstruídos, manipulados, transformados, etc. Creio que esse seja o trabalho do feminismo. (PRECIADO, 2010, p. 4)

Joan Scott é uma historiadora que influenciou bastante o movimento feminista a partir da década de 1980. Ela considera que o termo gênero surge contemporaneamente e primeiramente entre as feministas americanas para rejeitar o determinismo biológico que o sexo carrega.

\footnotetext{
${ }^{3}$ Refere-se ao ano da primeira edição da publicação de 1993 utilizada neste artigo.
} 
A autora trabalha de uma perspectiva relacional entre o homem e a mulher, evitando promover uma análise apenas do sexo oprimido (mulher), uma vez que para compreender a mulher faz-se necessário entender historicamente a sua relação com o homem.

Essa postura e escolha política da categoria gênero, enquanto relacional, foi fundamental para debater e combater a naturalização da opressão feminina e permitir que a história das mulheres saia da armadilha do patriarcalismo, sendo interpretada como uma história separada da dos homens e restrita ao cárcere privado da família e do sexo. Para superar essa hegemonia masculina que confere como protagonistas da história apenas os seus semelhantes (os homens) e invisibilizaram o Outro (a mulher), faz-se necessário utilizar o gênero como categoria de análise.

O desafio lançado por este tipo de reações é, em última análise, um desafio teórico. Ele exige a análise não só da relação entre experiências masculinas e femininas no passado, mas também a ligação entre a história do passado e as práticas históricas atuais. Como é que o gênero dá um sentido à organização e à percepção do conhecimento histórico? As respostas dependem do gênero como categoria de análise. (SCOTT, 1995, p. 75)

O que é mais relevante nesse caso é a percepção de que há um único mundo para homens e mulheres, além de perceber o gênero como "uma categoria social imposta sobre um corpo sexuado" (SCOTT, 1995, p. 77). O grande mérito de Scott foi discutir o corpo dentro do contexto cultural, influenciada por Derrida e Foucault, revelando que não há experiência corporal dissociada dos processos sociais e históricos de construção de significados. Desta maneira, a autora desnaturaliza o gênero, negando que ele seja uma determinação biológica, porém, considera a existência de diferenças corporais baseadas no sexo, que para ela são determinantes na construção do significado do gênero por meio das relações de desigualdades e poder.

Minha definição de gênero tem duas partes e várias subpartes. Elas são ligadas entre si, mas deveriam ser analiticamente distintas. [...] o gênero é um elemento constitutivo de relações sociais baseadas nas diferenças percebidas entre os sexos, e o gênero é uma forma primeira de significar as relações de poder. (SCOTT, 1995, p. 91) 
Baseado nessa definição do gênero, Scott discorre sobre as subpartes que a constitui, para poder deixar mais claro e justificar a sua teoria do gênero enquanto uma construção social. São elas: símbolos culturais; conceitos normativos; fixidez do gênero; identidade subjetiva. Através desses quatro elementos Scott identifica como o gênero poderá ser contestado a partir das lacunas deixadas por cada um desses caminhos.

Somos bombardeados por símbolos culturais que nos remetem ao binarismo de gênero, como é o caso de Eva e Adão na concepção cristã ocidental, que nos restringe a pensar além, uma vez que nos é imposto subliminarmente que só existem dois sujeitos sexuais (o homem e a mulher), que são detentores de gêneros inteligíveis (que há uma coerência heteronormativa entre sexo, sexualidade e desejo) e que há um superior (Adão) que o Outro (Eva - criada da costela de Adão). Temos outros exemplos de símbolos culturais que incidem diretamente na construção das fronteiras de gênero: "mundo econômico"/"mundo doméstico"; serviço braçal/serviço leve; posto de gerência/serviços secundários; virilidade/delicadeza.

Toda essa simbologia só é possível por conta do segundo elemento, os conceitos normativos, "que são expressos nas doutrinas religiosas, educativas, científicas, políticas ou jurídicas e tipicamente tomam a forma de uma oposição binária que firma de forma categórica e sem equívoco o sentido do masculino e do feminino." (SCOTT, 1995, p. 21)

Esse processo desencadeia a ideia de um gênero fixo (terceiro elemento), como algo pré-determinado e imutável, que tem sido objeto de negação dos pós-estruturalistas e da Teoria Queer, que contrariamente a essa ideia revela o sujeito fragmentado, fluído e em eterno trânsito. Desta maneira rompe com a concepção de um sujeito uno, desintegra o determinismo e no caso do gênero desconstrói a sua inteligibilidade.

Ao resistir às práticas discursivas e institucionais que, em seu funcionamento difuso e estendido contribuem para operação da heteronormatividade, as identidades queer podem abrir um espaço social para a construção de identidades diferentes, desenvolvendo vários tipos de relações e o desenvolvimento de novas formas culturais. (HALPERIN, 2007, p. 88, tradução nossa) 
É então que chegamos ao gênero enquanto uma identidade subjetiva (quarto elemento), da legitimação do gênero através dos discursos que recorrem à sexualidade e a fisiologia para justificar fenômenos sociais que nada tem a ver com o sexo, mas que reforçam a heteronormatividade.

As diferenças entre os corpos que são ligados ao sexo, são constantemente solicitadas para testemunhar as relações e fenômenos sociais que não tem nada a ver com a sexualidade. Não só testemunhar, mas testemunhar a favor, isto é, legitimar. (GODELIER apud SCOTT, 1995, p. 93)

E essa identidade subjetiva está ligada diretamente às relações de poder integrando atos performativos, ações e conceitos normativos à cultura. Nem sempre o uso do gênero é explícito para justificar desigualdades sociais, uma vez que a rede de relações sociais está tão permeada por discursos naturalizados em relação ao masculino e ao feminino, que acaba passando despercebido pelo oprimido e pelo opressor, faz com que a mulher não questione porque ela tem que ter uma jornada tripla de trabalho (trabalhos domésticos, cuidar dos filhos e trabalho profissional) enquanto o homem pode chegar em casa e se deitar no sofá, após ter trabalhado o mesmo período que a mulher. A mulher conquistou espaço no mercado de trabalho, mas ainda não se libertou do patriarcado nem da espécie.

Então chegamos a Beatriz Preciado, que também considera o gênero como fruto de uma construção social, e desenvolve seus estudos de forma teórica e política com base no desconstrucionismo pósestruturalista. Ela $(\mathrm{e})^{4}$ promove um estudo sobre a genealogia dos hormônios, tomando como referência as biotecnologias como processos de construção do gênero, apresentando-as como parte de um novo regime que se instaura para desenvolver o controle e a produção do corpo, que afirma ser uma lacuna deixada por Foucault e a Teoria Queer. "Por anos as feministas utilizaram a noção de gênero como construção social e cultural da diferença sexual, mas fazendo assim, perdemos de

${ }^{4}$ Beatriz Preciado se autorreferência no masculino e no feminino, uma vez que na verdade ela(e) gostaria que existisse um gênero neutro ao qual pudesse se designar, mas como precisa se comunicar com base na gramática existente, ela(e) decide borrar as normas e não se enquadrar em nenhum dos dois gêneros conhecidos, mas sim, posicionar-se enquanto um ser híbrido, nem um nem outro, os dois ao mesmo tempo. 
vista os processos biotecnológicos que nos trouxeram sua invenção." (Preciado, 2010, p. 12)

Diferentemente de Scott que se refere ao uso do termo gênero tomando como base apenas o feminismo, Preciado vai além, com uma estratégia para justificar sua tese. Ela(e) desenvolve seu argumento teórico a partir da criação do termo em 1947 pelo psiquiatra da infância, John Money, que idealizou o termo gênero para legitimar a intervenção cirúrgica e hormonal nos corpos dos bebês intersexuais.

Diante de seres humanos que a própria natureza questiona o binarismo sexual, uma vez que o(a) intersexual nasce com uma anatomia genital que condiz aos dois sexos conhecidos (masculino e feminino), a medicina cria o gênero como sendo flexível e tecnicamente construído, para poder determinar e enquadrar esses bebês dentro do binarismo sexual, jamais os dois ao mesmo tempo. A este movimento da medicina Preciado irá chamar de "essencialismo do tipo construcionista", em que há um ato de reconstruir para essencializar.

[...] as nossas identidades sexuais e de gênero são hoje resultado de um embate, de um confronto, também de tensão e uma luta entre três regimes de controle e produção do corpo: o regime soberano, (...) do disciplinário, (...) e por fim, o regime que utiliza um conjunto de novas técnicas que não são mais exteriores, mas biológicas. Se trata de moléculas, de fluidos que pela primeira vez entram a fazer parte do corpo e modificam a estrutura do vivente. (PRECIADO, 2010, p. 16)

Para o(a) autor(a) esse novo regime, a qual ele(a) nomeia de farmacopornográfico (fármaco referindo-se à biotecnologia e pornográfico em relação à indústria pornô), não substitui os demais regimes que controlam e produzem os corpos, as sexualidades e os gêneros, mas que em determinados momentos os sobrepõe.

No mesmo ano (1947) que se cria o termo gênero como um disciplinador médico do sexo é inventado o protocolo de transexualidade por Harry Benjamin, que legitima a patologização dos(as) transexuais e transgêneros, bem como a criação da pílula financiada pela igreja católica, a que Preciado relata ser um projeto "que parece ou se apresenta orientado para gestão da reprodução, é na realidade um 
projeto eugenético, vale dizer um projeto de purificação da raça, e é também um projeto de produção técnica da feminilidade" (PRECIADO, 2010, p. 18).

Essa conclusão a que Preciado chega sobre a pílula ocorre pela análise do contexto histórico sob o qual a pílula foi testada (em mulheres negras de uma comunidade de Porto Rico), que segundo ele(a) tinha como objetivo restringir a expansão da raça negra nos Estados Unidos. Outra curiosidade sobre a pílula é o seu uso para controle da homossexualidade.

Por outro lado, a pílula experimental dos anos 40 e 50 foi testada também nos hospitais psiquiátricos e nas prisões justamente para controlar a homossexualidade seja masculina ou feminina: pela primeira vez se utilizam hormônios para gestão da homossexualidade. É algo de absolutamente novo. No contexto psiquiátrico as lésbicas serão experimentalmente tratadas com a pílula, com uma técnica que a medicina imaginava que poderia heterossexualizar as mulheres. (PRECIADO, 2010, p. 19)

Estamos tod@s ligad@s direta ou indiretamente a um ou outro elemento dos processos fármacos da construção do gênero, seja o uso de hormônios para: o controle de um distúrbio (evitar pelos faciais em mulheres por exemplo); para combater doenças como o câncer; pra substituir quimicamente a ausência de um hormônio natural; para acelerar ou impedir o processo de reprodução; para realizar a redesignação sexual; dentre outros.

Saímos do Século XIX onde o principal regime de controle do corpo era o disciplinar, através das estruturas e discursos, para entrar no domínio do regime farmacopornográfico do século XX.

As técnicas de controle do corpo que, como eu falava, durante o século XIX eram fundamentalmente exteriores e rígidas $-[\ldots]$ foi transformada agora em uma técnica micropostética que o corpo pode ingerir transformando-se em uma parte de seu sistema biológico. (PRECIADO, 2010, p. 20)

Até agora só vimos uma parte do regime farmacopornográfico, referente às intervenções da bioteconologia. Veremos a partir deste momento a outra face do regime, a que se debruça sobre a pornografia como técnica 
de masturbação vinculada ao sistema de comunicação e produção do capital (indústria pornográfica).

Nesse capitalismo farmacopornográfico a produção do prazer, a produção da sexualidade, a produção dos afetos é transformada em uma força de produção de capital. Não é mais unicamente um elemento ou, se prefere, um braço da gestão política; agora é também uma das bases do capitalismo contemporâneo. (PRECIADO, 2010, p. 22)

É o sistema econômico que intervém na cultura, muda paradigmas seculares, tais como a masturbação que era interditada e agora é incentivada como uma ação de produção do prazer, mascarando seu real objetivo: o capital. O estímulo à pornografia surge com foco na masturbação peniana (sendo assim restrito ao masculino), além de reificar em suas representações as condições de superioridade do homem em relação à mulher.

Estamos nos 2000 e a sexualidade já está constantemente construída por meio de representações pornográficas e não é mais possível escolher a não representação da sexualidade porque sem representação não há sexualidade. A única coisa que podemos escolher é uma forma de proliferação crítica das representações sexuais. (PRECIADO, 2010, p. 26)

Para combater essa construção do gênero por parte da farmacopornografia, Preciado vê como única alternativa do feminismo a criação de alianças com as(os) trangêneros, os(as) transexuais e os(as) anticoloniais. Só unindo forças e diversificando os objetos e objetivos pelos quais se luta, será possível combater os diversos regimes de normalização do corpo e da sexualidade.

Desta maneira, da mesma forma que Scott se aproxima dos estudos de Foucault quando defende o gênero como uma construção social, Beatriz Preciado também bebe na teoria deste teórico, para pensar através da biopolítica ${ }^{5}$ dos corpos à produção do gênero, do sexo e da sexualidade

\footnotetext{
${ }^{5}$ A biopolítica é um conceito criado por Foucault para apresentar uma nova estrutura de poder, que vai se ocupar, portanto, com os processos biológicos relacionados ao homem-espécie, estabelecendo sobre os mesmos uma espécie de regulamentação que se dá por meio de múltiplos saberes, como a Estatística, a Demografia e a Medicina Sanitária.
} 
como dispositivos do saber e poder criados na modernidade, com as quais Preciado quer romper. Adepta(o) da Teoria Queer (que veremos na próxima sessão), o(a) autor(a) se diferencia de Judith Butller por exemplo, por seguir uma linha mais anárquica como estratégia intelectual, utilizando o próprio corpo como expressão teórico-política do processo fármaco, ao se autoaplicar testosterona para demonstrar que o gênero dela não pertence nem ao Estado, nem à família, nem a nenhuma instituição social.

\subsection{As sexualidades desviantes e a teoria queer}

Uma vez que já discutimos como a mulher e o gênero se constituem socialmente, partiremos agora para entender como a população trans feminina vivencia sua alteridade em relação à população cisgênero ${ }^{6}$.

Todos nós já nos deparamos com situações em que nos sentimos fora do eixo, incompreendidos(as), um peixe fora d'água, constrangidos(as), inadequados(as), ou seja, fora das normas e padrões em uma determinada situação de espaço e tempo. Não é uma situação muito agradável. Agora imagine quem passa por esse processo a todo o momento e em todos os espaços sociais, isso é o que ocorre com as travestis, transexuais e transgêneros nesse mundo heteronormativo em que vivemos.

Est@s sujeit@senfrentam uma batalha todos os dias, só pelo fato de não fazerem parte dos grupos de gênero inteligível, ou seja, não seguem a principal premissa da heteronormatividade (termo criado por Michael Warner em 1991), em que o sujeito deve ter desejo sexual pelo sexo oposto, a sua identidade de gênero deve coincidir com o seu sexo

\footnotetext{
${ }^{6}$ Cisgênero, cissexual ou apenas cis é iden,tificado como uma estratégia política de tornar o(a) heterossexual e as pessoas de gênero inteligível no Outro, fazendo uso da alteridade. É uma terminologia transfeminista para desnaturalizar as identidades consideradas "naturais". Da mesma forma que a ciência criou o termo trans (já constituído com uma representação marginalizada), a população trans inverte o processo e nomeia os(as) "normais" para que possam ser analisados, questionados e objeto de crítica. É um termo da década de 90 e que também pode ser utilizado para representar os(as) não-trans. Neste ensaio será utilizado para identificar os homens e mulheres heterossexuais.
} 
biológico e seus prazeres estarem dentro dos padrões heterossexuais. Sendo assim:

Gêneros "inteligíveis" são aqueles que, em certo sentido, instituem e mantêm relações de coerência e continuidade entre sexo, gênero, prática sexual e desejo. Em outras palavras, os espectros de descontinuidade e incoerência, eles próprios só concebíveis em relação a normas existentes de continuidade e coerência, são constantemente proibidos e produzidos pelas próprias leis que buscam estabelecer linhas causais ou expressivas de ligação entre o sexo biológico, o gênero culturalmente constituído e a "expressão" ou "efeito" de ambos na manifestação do desejo sexual por meio da prática sexual. (BUTLER, 2003, p. 38)

A heteronormatividade é um termo que tem uma relação direta com a expressão heterossexualidade compulsória, desenvolvida pela feminista norte-americana Adrienne Rich em um ensaio de 1980 publicado em 1986 com o título "Compulsory Heterosexuality and Lesbian Existence". A heteronormatividade atua como um dispositivo histórico da sexualidade, que foi uma característica fixada a partir da família patriarcal, e tem como objetivos: disciplinar tod@s para serem heterossexuais e/ou, independente da sexualidade, induzir a tod@s as pessoas viverem dentro dos padrões e normas heterossexuais.

É esta heteronormatividade que resulta na performatividade de gênero, onde o homem cis deve seguir os parâmetros construídos como sendo do sexo masculino, como por exemplo: ser másculo, viril, sentir atração por mulheres, ter filho, gostar de futebol, trabalhar fora de casa e coisas do tipo e o mesmo acontece com a mulher cis, que dever ser: sensível, vaidosa, sentir atração por homens, cuidar da educação dos filhos e dos serviços domésticos e assim por diante, ou seja, através dos discursos os seres nascem sabendo que existem apenas dois gêneros: o masculino e o feminino e que estes gêneros estão ligados diretamente ao sexo biológico ao qual pertencem.

Para atender as exigências da heteronormatividade fazemos uso da performatividade de gênero. É importante compreendermos que performatividade difere-se de performance, pois no primeiro caso é uma criação imposta pelas instituições sociais e que a sociedade a repete como uma verdade essencial, enquanto performance podemos, em 
síntese, dizer que se trata de uma encenação teatral. Podemos ver isto na citação de Butler: "Los actos performativos son modalidades de discurso autoritário: la mayoría de ellos, por ejemplo, son afirmaciones que, al enuciarse, también encarnan uma acción y ejercen um poder vinculante." (BUTLER, 2002, p. 56) e que podemos complementar com outra citação desta autora contida em seu famoso livro Corpos que Pesam, sendo um capítulo do livro traduzido e organizado por Guacira Lopes:

A performatividade não é, assim, um "ato" singular, pois ela é sempre uma reiteração de uma norma ou conjunto de normas. E na medida em que ela adquire o status de ato no presente, ela oculta ou dissimula as convenções das quais ela é uma repetição. Além disso, esse ato não é primariamente teatral; de fato, sua aparente teatralidade é produzida na medida em que sua historicidade permanece dissimulada (e, inversamente, sua teatralidade ganha uma certa inevitabilidade, dada a impossibilidade de uma plena revelação de sua historicidade). (BUTLER, 2000, p. 121)

Através do discurso o gênero se materializa e ganha contornos por meio de um processo de inclusão/exclusão, autorizado/proibido que define o humano/inumano e o normal/estranho. "O gênero é um constructo social que é formado ao longo do tempo através da reiteração de normas" (idem). As normas são regidas pela heteronormatividade que trabalha com o princípio da binaridade onde só pode existir uma coisa ou outra, ganhando o caráter de abjeto tudo aquilo que não se encaixa nesse padrão de fixidez. Sendo assim, "fazemos gênero o tempo inteiro, somos fazedores de gênero."(BENTO, 2014) ${ }^{7}$

Antes era necessário ter um Estado que coagisse os cidadãos a terem um comportamento adequado, mas hoje essa dominação social pelo Estado não se faz necessária, tendo em vista que a dominação assume novas formas mais difíceis de serem combatidas, tais como as vizinhanças, as escolas, as famílias, as igrejas, os amigos e todas as demais instituições sociais, como resultado do patriarcalismo pós-moderno, conforme podemos verificar na referência a Foucault:

\footnotetext{
7 Em entrevista cedida a Diego Madi Dias e publicada no Caderno Pagu $n^{\circ} 43$ Campinas July/Dec 2014.
} 
O Estado já não necessita intimidar ou coagir os sujeitos para que tenham um comportamento adequado; pode, com toda seguridade, deixar que tomem suas próprias decisões sob a sacrossanta esfera privada da liberdade pessoal em que habitam agora, porque dentro dessa esfera eles controlam livre e espontaneamente sua própria conduta e a dos demais. (HALPERIN, 2007, p. 37, tradução nossa)

Quando a população trans foge das normas determinadas pelo grupo hegemônico por causa da desarmonia entre sua performatividade de gênero e o seu sexo biológico, provoca atos repulsivos e de abjeção da/na sociedade, uma vez que estes sujeitos borram a concepção de gênero, que é uma questão central nas relações de poder e se tornou hoje um assunto de Estado. Temos então corpos abjetos:

O abjeto designa aqui precisamente aquelas zonas "inóspitas" e "inabitáveis" da vida social, que são, não obstante, densamente povoadas por aqueles que não gozam do status de sujeito, mas cujo habitar sob o signo de “inabitável” é necessário para que o domínio do sujeito seja subscrito. (BUTLER in LOURO, 2000, p. 153)

É então que acontece por parte da sociedade um ato repulsivo a estes(as) atores/atrizes sociais que não estão inseridos(as) no modelo hegemônico, levando-os(as) a cometer atos homofóbicos e transfóbicos, gerando a partir daí a performatividade queer, que segundo Butller tem o objetivo de criar fissuras e contra-discursos. "El término queer surge como uma interpelación que plantea la cuestión de la fuerza y de la oposición, de la estabilidad y la variabilidad em el seno de la performatividad" (BUTLER, 2002, p.58). E ainda diz: “Queer adquiere todo su poder precisamente através de la invocación reiterada que lo relaciona com acusaciones, patologias e insultos." (ídem).

Nesse sentido, ao pensar a diferença optamos pelos fundamentos da Teoria Queer como um movimento, uma disposição existencial e política que supõe a ambiguidade, o não lugar e o trânsito. Um conjunto de saberes, uma disposição política que vem promovendo novas políticas de conhecimento cultural (LOURO, 2012).

Os estudos queer surgem em meados da década de oitenta e ganham notoriedade na década de 1990, como fruto dos Estudos-Culturais Americanos fazendo parte do conjunto das teorias subalternas, que são 
as que fazem uma crítica aos discursos hegemônicos na cultura ocidental. A teoria queer difunde o discurso de um mundo sem rótulos, podendo cada sujeito ser como quiser e da forma que quiser no que tange ao gênero. Saem do binarismo do homem/mulher para multiplicidades de gêneros. Para o queer não há certo ou errado, há apenas o diverso. "Queer pode ser traduzido por estranho, talvez ridículo, excêntrico, raro, extraordinário", diz Louro (2004, p. 38).

A teoria queer se propõe a analisar a constituição dos sujeitos e suas identidades através das experiências culturais vivenciadas, com foco na crítica dos discursos normalizantes, hegemônicos e universalizantes, subvertendo o binarismo sexual dado e revelando a possibilidade da multiplicidade identitária possível.

Queer é tudo isso: estranho, raro, esquisito. Queer é, também, o sujeito da sexualidade desviante homossexuais, bissexuais, transsexuais, travestis, drags. É o excêntrico que não deseja ser "integrado" e muito menos "tolerado". Queer é um jeito de pensar e de ser que não aspira o centro nem o quer como referência; um jeito de pensar e de ser que desafia as normas regulatórias da sociedade, que assume o desconforto da ambigüidade, do "entre lugares", do indecidível. Queer é um corpo estranho, que incomoda, pertuba, provoca e fascina. (LOURO, 2004, p. 07-08)

Podemos considerar a população trans sujeitos queer, uma vez que são excêntricos, misturam a performatividade do masculino e feminino, rompem com a inteligibilidade, afirmam-se enquanto diferentes e ocupam um lugar de trânsito, em maior ou menor grau devido a diversidade desse grupo?

\section{Considerações Finais}

Ainda temos um longo caminho a percorrer para transpor barreiras e superar tabus e preconceitos a respeito das identidades de gênero, tendo exemplos cada vez mais recorrentes de sexismo, misoginia, homofobia e transfobia sendo notícia nas mais diversas mídias, ao mesmo tempo, uma sociedade organizada e militância cada vez mais preparada e 
predisposta a alcançar um ambiente favorável à implementação da Cultura da Diversidade.

Nesse mundo complexo, repleto de identidades fluídas e múltiplas, ainda imperam sistemas de opressão que desejam permanecer presos à fixidez das identidades traçadas pelas normas. E quando tratamos de gênero temos o patriarcalismo e a heteronormatividade como principais ideologias propulsoras desse enquadramento $\mathrm{d} @ \mathrm{~s}$ que são considerad@s abjetos. A partir dessas duas ideologias que se complementam e retroalimentam, chegamos a um sistema binário do sexo, em que só deve existir o masculino e o feminino. Qualquer variação dessas duas categorias será rechaçada, punida ou convidada ao enquadramento nas normas pré-estabelecidas.

É então que chegamos à comunidade trans feminina como representantes dess@s sujeit@s abjetos, que na maioria dos casos contrariam a sua identidade de gênero pelo viés da biologia, que o gênero deve seguir uma coerência com o sexo (genital) com o qual se nasce, mas adotam as normas sociais pré-estabelecidas para @s sujeit@s cis da identidade de gênero a qual assumiram, tentando se assemelhar ao máximo do referencial de mulher que é conhecido, ou seja, rendem-se ao binarismo e consideram que devem seguir os padrões normativos que definem o que é ser feminino. Já em outros casos, @s sujeit@s preferem manter-se literalmente na fronteira, no entre-lugar e não se enquadrar em nenhuma das identidades normativas, são e querem ser reconhecidas como uma outra categoria, evidenciando a falência do sistema binário e revelando o múltiplo.

\section{Referências}

BAUMAN, Zygmunt. Identidade: entrevista a Benedetto Vecchi. Tradução Carlos Alberto Medeiros. Rio de Janeiro: Jorge Zahar, 2005.

BUTLLER, Judith. Corpos que pesam: sobre os limites discursivos do "sexo". In: LOURO, Guacira L. (Org.). O corpo educado: Pedagogias da sexualidade.. 2. ed. Belo Horizonte: Autêntica, 2000, pp. 151-172. 
.Criticamente Subversiva. In: Jiménez, Rafael M. M. (Org.). Sexualidades Transgressoras: uma antologia de estúdios queer. Barcelona: Icaria, 2002, pp. 55-79.

Problemas de gênero: feminismo e subversão da identidade. Tradução Renato Aguiar. Rio de Janeiro: Civilização Brasileira, 2003.

CASTELLS, Manuel. O poder da Identidade - A era da informação: economia, sociedade e cultura. V. 2 ed. 6. São Paulo: Paz e Terra, 1999.

ENNES, M. A.; MARCON, F. N. Das identidades aos processos identitários: repensando conexões entre cultura e poder. Sociologias (UFRGS. Impresso), v. 16, p. 12-34, 2014.

HALPERIN, David. "La política queer de Michel Foucault". In: HALPERIN, David. San Foucault: para una hagiografía gay. Tradução Mariano Serrichio. Argentina: Ed. Literales, 2007. p.p. 33159.

LOURO, Guacira Lopes. O corpo estranho. Ensaios sobre sexualidade e teoria queer. Belo Horizonte: Autêntica, 2004.

Os Estudos Queer e a Educação no Brasil: articulações, tensões, resistências. Contemporânea - Revista de Sociologia da UFSCar. São Carlos, v. 2, n.2, jul-dez 2012, pp. 363-369.

PATEMAN, C. O Contrato Sexual. São Paulo/Rio de Janeiro, Paz e Terra , 1993.

PRECIADO, Beatriz. Transfeminismo no Regime Farmacopornográfico. In: Conferência Le cinque gio rnate lesbiche in teoria. Tradução Thiago Coacci. Roma 02 a 06 de Jinho de 2010.

SCOTT, J. W. Gênero: uma categoria útil para análise histórica. Educação \& Realidade. 1995. p. 71-99.

Recebido em 15/03/2017

Aprovado em 15/07/2017 